\title{
Struktur Komunitas Moluska dan Kualitas Perairan di Kawasan Hutan dengan Tujuan Khusus Carita, Pandeglang, Banten
}

\author{
Berti Priska Gea $^{1)^{*}}$, Budi Rahayu$^{1)}$, Silfi Faizatuluhmi ${ }^{1)}$, Ratna Komala ${ }^{1)}$ \\ ${ }^{1)}$ Fakultas Matematika dan IImu Pengetahuan Alam, Universitas Negeri Jakarta, Jl. Pemuda No.10, Jakarta Timur, \\ Jakarta, Indonesia \\ ${ }^{*}$ Email korespondensi: bertipriska88@gmail.com
}

\begin{abstract}
ABSTRAK
Moluska adalah salah satu bioindikator pencemaran lingkungan yang sebagian besar spesiesnya di Indonesia belum banyak diungkap sehingga menarik untuk dipelajari lebih dalam. Moluska dapat ditemukan di perairan laut dan tawar di Pantai Carita, Pandeglang. Tujuan dari penelitian ini adalah untuk mempelajari struktur komunitas Moluska di perairan laut dan tawar serta penentuan kualitas perairan. Penelitian dilaksanakan di Kawasan Hutan dengan Tujuan Khusus (KHDTK), Kecamatan Carita, Kabupaten Pandeglang, Banten. Metode penelitian yang digunakan adalah kuantitatif deskriptif. Sampel Moluska dikumpulkan dari tiga kuadran dengan masing-masing ukuran $1 \times 1 \mathbf{~ m}^{2}$ berdasarkan garis transek. Identifikasi dan analisis data dilakukan berdasarkan kelimpahan, indeks keanekaragaman dan dominansi. Sampel yang teridentifikasi didominasi oleh Gastropoda dibandingkan Bivalvia. Indeks keanekaragaman Moluska di perairan laut adalah 0,37, 0,36, dan 0,32, sementara di perairan tawar adalah $0.36,0.36$, dan 0.37. Indeks dominansi Moluska di perairan tawar adalah $0.12,0.21$, dan 0.04 sedangkan di perairan tawar adalah $0.08,0.10$, dan 0.17 . Spesies melimpah di perairan laut adalah Laevipilina cachuchensis, Rhinoclavis vergatus, Mactra grandis, Trachycardium subrugosum, dan Morula margariticola sedangkan spesies dominan di perairan tawar adalah Thiara Scabra. Kualitas dari perairan tawar maupun laut termasuk kategori baik untuk mendukung kehidupan Moluska.
\end{abstract}

Kata kunci: Bivalvia, Gastropoda, kelimpahan, keanekaragaman, dominansi

\section{Structure of Mollusc Community and Water Quality in the Forest Area for Special Purpose Carita, Pandeglang, Banten}

\author{
Berti Priska Gea $^{1)^{*}}$, Budi Rahayu ${ }^{1)}$, Silfi Faizatuluhmi ${ }^{1)}$, Ratna Komala ${ }^{1)}$ \\ ${ }^{1)}$ Faculty of Mathematics and Natural Sciences, Universitas Negeri Jakarta, Jl. Pemuda No.10, East Jakarta, \\ Jakarta, Indonesia \\ ${ }^{*}$ Email: bertipriska88@gmail.com
}

\begin{abstract}
Molluscs are one of the bioindicators of environmental pollution, which most of the species in Indonesia have not been revealed hence it is interesting to study them more deeply. The Molluscs can be found in marine and fresh water located in Carita Beach, Pandeglang. The aims of the research were to study the community structure of Molluses in marine and fresh water, and to identify the quality of the water. The research was conducted in the Forest Area for Special Purpose, Carita District, Pandeglang Regency, Banten. The research method used was quantitative descriptive. Molluse samples were collected from three quadrants based on the transect line $1 \times 1 \mathrm{~m}^{2}$. Data identification and analysis was carried out based abundance, diversity and dominance. The samples identified were dominated by Gastropods rather than Bivalves. The Mollusc diversity index in marine waters was $0.37,0.36$, and 0.32 , while in freshwater were $0.36,0.36$ and 0.37 . The dominance index of molluses in fresh waters was $0.12,0.21$ and 0.04 while in freshwater were $0.08,0.10$ and 0.17 . The species abundant in marine waters were Laevipilina cachuchensis, Rhinoclavis vergatus, Mactra grandis, Trachycardium subrugosum, and Morula margariticola while the dominant species in freshwater was Thiara scabra. The quality of fresh and marine waters was in the good category for the growth of the Molluses.
\end{abstract}

Keywords: Bivalvia, Gastropod, abundance, diversity, dominance 


\section{PENDAHULUAN}

Komunitas makhluk hidup dapat diklasifikasikan berdasarkan bentuk atau sifat struktur utama seperti spesies dominan, bentuk hidup atau indikator, habitat fisik dari komunitas dan sifat-sifat atau tanda-tanda fungsional. Pada komunitas tersebut akan terbentuk struktur komunitas yang bersifat stabil maupun labil tergantung pada faktor lingkungan yang memengaruhinya [1].

Struktur komunitas yaitu suatu konsep yang mempelajari susunan atau komposisi spesies dan kelimpahannya dalam suatu komunitas [2]. Secara umum ada tiga pendekatan yang dapat digunakan untuk menggambarkan struktur komunitas yaitu keanekaragaman spesies, interaksi spesies dan interaksi fungsional [3]. Struktur komunitas dapat dipelajari melalui komposisi, ukuran dan keanekaragaman spesies yang terkait erat dengan kondisi habitat. Perubahan pada habitat akan berpengaruh terhadap struktur komunitas karena perubahan habitat akan berpengaruh pada tingkat spesies sebagai komponen terkecil penyusun populasi dalam komunitas. Salah satu organisme penyusun ekosistem daerah dasar perairan yaitu bentos seperti Moluska [4].

Moluska bisa ditemukan di perairan laut maupun tawar. Filum Moluska dengan anggota terbanyak adalah Gastropoda. Kecenderungan dan aktivitas Gastropoda sangat dipengaruhi oleh kondisi pasang surut air laut dan ketersediaan makanan. Gastropoda hidup di daerah pasang surut sampai kedalaman enam meter dengan dasar berlumpur pasir yang banyak ditumbuhi alga. Gastropoda umumnya ditemukan di antara karang yang banyak tersedia bahan makanan atau pada daerah yang bisa menjamin keberlangsungan hidupnya. Secara umum Moluska yang hidup di laut ditemukan pada zona litoral atau di laut dangkal [5].

Perairan pantai sangat penting sebagai habitat berbagai jenis organisme. Perairan pantai merupakan daerah peralihan antara perairan tawar dan laut, terutama di daerahdaerah dekat muara sungai. Kondisi perairan pantai yang baik, tidak hanya akan menguntungkan secara ekologis, tetapi juga merupakan sumber penghidupan bagi masyarakat, baik secara langsung bagi masyarakat nelayan maupun secara tidak langsung bagi masyarakat lainnya. Pantai Carita merupakan salah satu pantai di pesisir barat Provinsi Banten, Indonesia. Secara geografis Pantai Carita terletak di Kabupaten Pandeglang dan telah ditetapkan berdasarkan SK Menteri Pertanian No.440/kpts/UM/1978 pada tanggal 15 Juli 1978 sebagai Taman Wisata Alam Perairan Pantai.

Menurut Dibyowati [6], kawasan Pandeglang terdiri dari berbagai variasi substrat sebagai habitat Moluska. Namun, substrat paling dominan adalah pasir dan karang. Hasil penelitian menunjukkan terdapat 34 jenis Moluska yang termasuk dalam Bivalvia dan Gastropoda. Pemanfaatan berlebih atau kurangnya pengawasan terhadap perairan tawar dan laut di sekitar Hutan Raya Pandeglang menimbulkan ancaman bagi keanekaragaman hayati. Kerusakan habitat seperti tempat hidup atau substrat bagi Moluska terjadi akibat berbagai aktivitas wisata dan perikanan yang tidak mengindahkan etika lingkungan hidup. Berbagai potensi kerusakan ini memicu peneliti untuk mengidentifikasi struktur komunitas Moluska di daerah Pantai Carita dan perairan tawar Kawasan Hutan dengan Tujuan Khusus (KHDTK) serta analisis fisikakimia perairan laut dan tawar.

Kawasan Hutan dengan Tujuan Khusus adalah salah satu tempat wisata yang banyak dikunjungi karena terdapat objek wisata pantai serta pemandangan wisata alam. Peneliti tertarik untuk menyelidiki pengaruh aktivitas manusia terhadap perkembangan Moluska di kawasan pantai maupun perairan yang semakin tinggi penggunaannya oleh warga setempat maupun wisatawan. Menurut hasil penelitian, terdapat 16 famili Moluska, terdiri dari 34 spesies Bivalvia dan 31 Gastropoda [6]. Analisis kualitas fisika dan kimia di perairan Pantai Carita menunjukkan bahwa pantai tersebut mengandung logam $\mathrm{Pb}$ dengan kadar cukup tinggi.

Akurasi dan aktualisasi data mendorong penelitian dilakukan sehingga perlu mengidentifikasi atau meninjau kembali keanekaragaman Moluska sehingga data yang ditampilkan menjadi data akurat sebagai dasar tindakan ekologi dalam menjaga hutan Pandeglang sebagai sumber daya alam yang lestari. Oleh karena itu, penelitian ini bertujuan untuk mengetahui struktur komunitas Moluska melalui identifikasi, analisis kelimpahan, keanekaragaman Moluska, dan spesies dominan serta untuk menentukan kualitas perairan di wilayah Pantai Carita dan Perairan Tawar Kawasan Hutan dengan Tujuan Khusus 
(KHDTK) dan identifikasi parameter fisika dan kimia perairan tawar dan laut.

\section{METODE PENELITIAN}

Tempat dan waktu. Penelitian ini dilaksanakan pada tanggal 2-5 Agustus 2018. Lokasi penelitian berada di Kawasan Hutan Dengan Tujuan Khusus (KHDTK), Desa Sukarame, Kecamatan Carita, Kabupaten Pandeglang, Banten (Gambar 1).

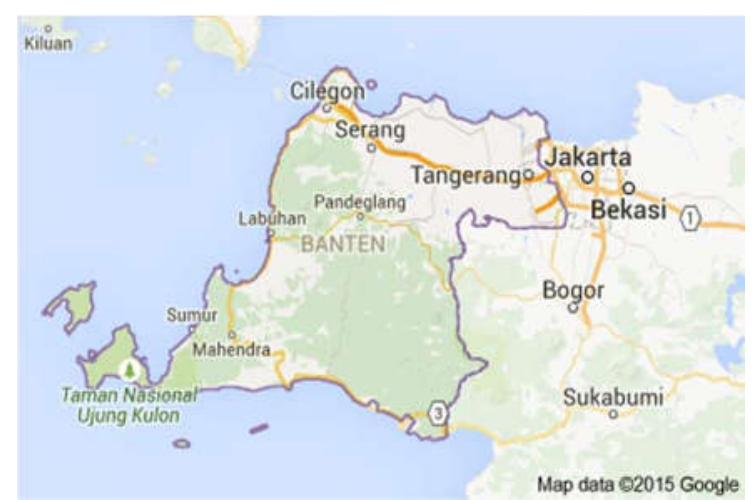

Gambar 1. Peta lokasi penelitian

Alat dan bahan. Alat yang digunakan dalam penelitian ini meliputi meteran, kerangka kuadran ukuran $1 \times 1 \mathrm{~m}^{2}$, pasak kayu (empat buah), secchi disc, Ekman grab, botol dan plastik sampel, baki plastik, saringan, mistar, DO meter, sekop, current meter, pipa paralon, termometer, alat tulis, dan kamera. Adapun bahan yang digunakan yaitu terdiri dari akuades, formalin 3\%, alkohol $70 \%$, kertas label, kertas lakmus, dan tali rafia.

Pemilihan lokasi sampling. Pemilihan lokasi pengambilan sampel Moluska dilakukan secara purposive sampling dengan menggunakan metode transek garis. Transek garis adalah garis memotong ke arah seberang batas komunitas tertentu yang akan diamati. Pada setiap stasiun diletakkan satu garis transek yang terdiri dari tiga kuadran masingmasing berukuran $1 \times 1 \mathrm{~m}^{2}$ sehingga total terdapat tiga transek garis dengan jarak 3-4 meter.

Pengambilan sampel Moluska dilakukan di wilayah intertidal dengan tiga titik pengambilan yang berjarak sekitar 1,5,10 meter dari bibir pantai. Sampel dikumpulkan dengan Ekman grab dan dimasukkan ke tabung [7]. Sampel Moluska yang diperoleh kemudian diidentifikasi berdasarkan sumber referensi dari [8-11].
Analisis Data. Jumlah individu Moluska yang ditemukan kemudian digunakan untuk menghitung kelimpahan per luas area dan indeks keanekaragaman di lokasi penelitian. Untuk penghitungan kelimpahan, indeks diversitas, dan indeks dominansi digunakan persamaan sebagai berikut, [12].

a. Kelimpahan

Kelimpahan : $A=\frac{X i}{n i}$

Keterangan :

$\mathrm{A}=$ Kelimpahan individu (ind $/ \mathrm{m}^{2}$ )

$\mathrm{Xi}=$ Jumlah individu dari jenis ke- $\mathrm{i}$

ni $=$ Jumlah luasan transek ke-i yang ditemukan

b. Indeks keanekaragaman (H') dan Dominansi (C)

Indeks keanekaragaman yang digunakan adalah indeks Shannon-Wiener yang diterapkan pada komunitas acak dengan ukuran yang besar, dimana jumlah total spesies diketahui. Indeks keanekaragaman dihitung dengan rumus:

$$
H^{\prime}=\sum_{i=1}^{s} p i 1 n p i
$$

Keterangan:

H' = Indeks Keanekaragaman ShannonWiener

$\mathrm{S}=$ Jumlah spesies

$\mathrm{Pi}=$ Proporsi jumlah individu/sampel pada spesies tersebut

dengan kriteria:

$\mathrm{H}^{\prime}<2 \quad$ : keanekaragaman rendah

$2<\mathrm{H}^{\prime}<3$ : keanekaragaman sedang

$\mathrm{H}^{\prime}>3$ : keanekaragaman tinggi

Semakin besar nilai $\mathrm{C}$ maka nilai $\mathrm{H}^{\prime}$ semakin kecil, yang mengisyaratkan adanya dominansi suatu spesies terhadap spesies lain. Dominansi yang cukup besar akan mengarah pada komunitas yang labil maupun tertekan. Indeks dominansi diperoleh dari perhitungan dengan menggunakan rumus:

$$
C=\sum_{i=1}^{s} p i^{2}
$$

$\mathrm{C}<0.5 \quad:$ dominansi rendah

$0.5<\mathrm{C}<0.75$ : dominansi sedang

$0.75<\mathrm{C}<1 \quad$ : dominansi tinggi 


\section{HASIL DAN PEMBAHASAN}

Hasil identifikasi spesies dan kelimpahan. Hasil identifikasi spesies Moluska di perairan laut KHDTK Pandeglang memberikan informasi bahwa Gastropoda lebih dominan daripada kelompok hewan yang lain. Kelas Gastropoda ditemukan sebanyak 33 spesies sedangkan Bivalvia sebanyak tiga spesies dan Monoplacophora sebanyak satu spesies (Tabel 1).

Famili terbanyak adalah Trochidae sebanyak tujuh spesies, famili Conidae sebanyak empat spesies, dan famili Cerithiidae sebanyak tiga spesies, sedangkan famili lainnya rata-rata satu hingga dua spesies (Gambar 2). Jumlah spesies dari tiga stasiun di sekitar Pantai Carita wilayah KHDTK adalah 37 spesies dengan persentase Gastropoda $88,89 \%$, Bivalvia 8,33\%, dan Monoplacophora 2,78\%. Hasil identifikasi spesies Moluska di perairan tawar KHDTK Pandeglang secara keseluruhan didominasi oleh Kelas Gastropoda dengan Famili Pachychilidae, Viviparidae,
Thiaridae dan Lymnaeidae (Gambar 2). Spesies dominan yang ditemukan adalah Laevipilina cachuchensis, Rhinoclavis vergatus, Mactra grandis, Trachycardium subrugosum, and Morula margariticola sedangkan di perairan tawar adalah Thiara scabra (Tabel 1).

Berdasarkan hasil penelitian lain menyatakan bahwa spesies Gastropoda lebih banyak daripada spesies Bivalvia seperti penelitian yang dilakukan oleh Monalisha dan Edward [13] yang menyatakan bahwa terdapat 44 spesies Gastropoda, 23 spesies Bivalvia, dan tiga spesies Cephalopoda. Sedangkan penelitian oleh Anandaraj et al [14] menyatakan bahwa terdapat 20 spesies Gastropoda dan 20 spesies Bivalvia di perairan laut Tamil Nadu. Menurut Datta et al [15] juga melaporkan bahwa terdapat 41 spesies Gastropoda dan lima spesies Bivalvia di perairan India. Namun, jika diakumulasikan maka Bivalvia terdiri dari 1100 spesies sedangkan Gastropoda 190 spesies.

Tabel 1. Hasil identifikasi spesies dan kelimpahan

\begin{tabular}{|c|c|c|c|c|c|c|}
\hline \multirow[b]{2}{*}{ Kelas } & \multicolumn{4}{|c|}{ Perairan Laut } & \multicolumn{2}{|c|}{ Perairan Tawar } \\
\hline & Nama Spesies & $\begin{array}{l}\text { Kelimp- } \\
\text { ahan } \\
\left(\mathrm{ind} / \mathrm{m}^{2}\right)\end{array}$ & Nama Spesies & $\begin{array}{l}\text { Kelimp- } \\
\text { ahan } \\
\left(\text { ind } / \mathbf{m}^{2}\right)\end{array}$ & Nama Spesies & $\begin{array}{c}\text { Kelimp- } \\
\text { ahan } \\
\left(\text { ind } / \mathbf{m}^{2}\right)\end{array}$ \\
\hline \multirow[t]{17}{*}{ Gastropoda } & Anadara granos & 0,33 & Mauritia arabica & 0,67 & Filopaludina javanica & 0,89 \\
\hline & Angaria delpinus & 0,33 & Morula margariticola & 2,67 & Radix rubiginosa & 0,44 \\
\hline & Cantharus undosus & 1,33 & Nerita chamaeleon & 0,67 & Sulcospira testudinaria & 1,67 \\
\hline & Certihidea quoyii & 0,33 & Notocochlis gualteriana & 0,44 & Thiara scabra & 4,56 \\
\hline & Clanculus gulneensis & 1,00 & Ovastipsa chinensis & 0,33 & & \\
\hline & Codakia tigerina & 0,33 & Pleoploca trapezium & 0,67 & & \\
\hline & Colubraria muricate & 1,00 & Pugilina cochlidium & 0,67 & & \\
\hline & Columbella scripta & 1,00 & Rhinoclavis aspera & 0,33 & & \\
\hline & Conus ebraeus & 0,70 & Rhinoclavis sinensis & 1,67 & & \\
\hline & Conus eburneus & 0,33 & Rhinoclavis vertagus & 1,26 & & \\
\hline & Conus lividus & 0,33 & Strombus urceus & 0,33 & & \\
\hline & Cymantium vespaceum & 0,33 & Tegula rugosa & 0,33 & & \\
\hline & Erosaria lamarckii & 0,33 & Trochus niloticus & 0,67 & & \\
\hline & Eucithara stromboides & 0,33 & Trochus tentorium & 1,00 & & \\
\hline & Euplica scripta & 0,33 & Umbonium elegans & 0,67 & & \\
\hline & Indothias gradate & 0,67 & Umbonium vestiarium & 1,00 & & \\
\hline & Mactra grandis & 2,00 & & & & \\
\hline \multirow{3}{*}{ Bivalvia } & Paphia gallus & 0,33 & & & & \\
\hline & $\begin{array}{l}\text { Trachycardium } \\
\text { rogusum }\end{array}$ & 0,33 & & & & \\
\hline & $\begin{array}{l}\text { Trachycardium } \\
\text { subrugosum }\end{array}$ & 1,67 & & & & \\
\hline $\begin{array}{l}\text { Mono- } \\
\text { placophora }\end{array}$ & $\begin{array}{l}\text { Laevipilina } \\
\text { cachuchensis }\end{array}$ & 4,00 & & & & \\
\hline
\end{tabular}

Pada perairan laut di Pantai Carita dengan kecepatan deburan ombak tergolong sedang menyebabkan Bivalvia yang memiliki alat gerak terbatas menjadi kurang adaptif. Namun daerah pesisir Pantai Carita relatif dipenuhi karang dan bersubstrat pasir sehingga 
memungkinkan keduanya hidup. Gastropoda dan Bivalvia menghindari daerah terbuka yang terkena deburan ombak maupun sinar matahari sehingga keduanya memanfaatkan celah bebatuan untuk bertahan hidup [16].

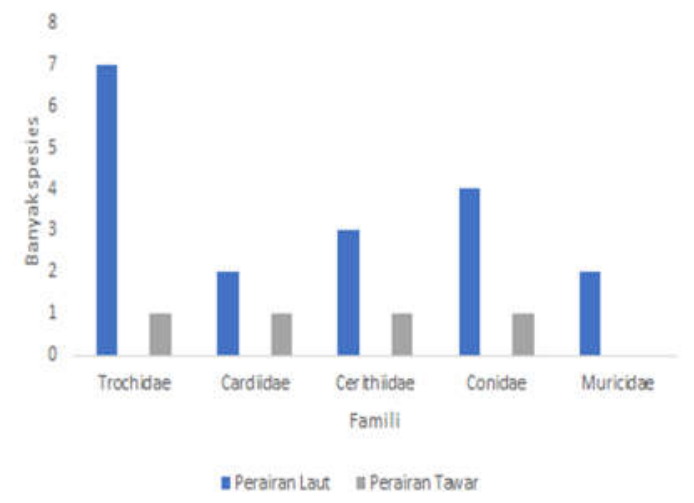

Gambar 2. Kelimpahan spesies Moluska yang ditemukan di perairan laut dan tawar area penelitian.

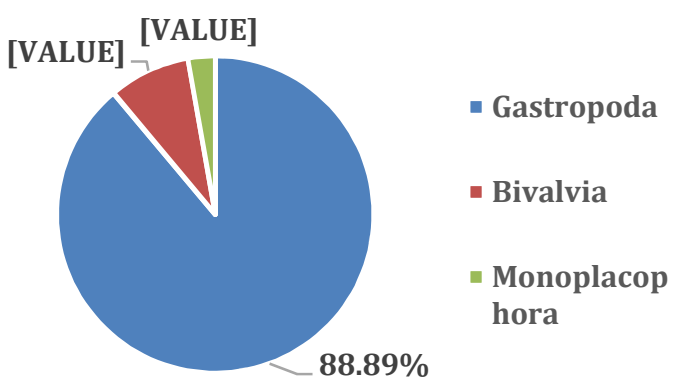

Gambar 3. Persentase kelimpahan Moluska.

Indeks keanekaragaman dan dominansi. Indeks keanekaragaman dan dominansi Moluska di perairan laut lebih rendah daripada perairan tawar seperti ditampilkan pada Tabel 2 berikut.

Tabel 2. Nilai indeks keanekaragaman dan dominansi Moluska di perairan laut dan tawar.

\begin{tabular}{lccc}
\hline Perairan & Stasiun & $\begin{array}{c}\text { Keanekaragaman } \\
\left(H^{\prime}\right)\end{array}$ & $\begin{array}{c}\text { Dominansi } \\
\text { (D) }\end{array}$ \\
\hline Laut & 1 & 0,37 & 0,12 \\
& 2 & 0,36 & 0,21 \\
\multirow{3}{*}{ Tawar } & 3 & 0,32 & 0,04 \\
& 1 & 0,36 & 0,08 \\
& 2 & 0,36 & 0,10 \\
& 3 & 0,37 & 0,17 \\
\hline
\end{tabular}

Berdasarkan Tabel 1 menunjukkan bahwa spesies dominan yang ditemukan adalah Laevipilina cachuchensis, Rhinoclavis vergatus, Mactra grandis, Trachycardium subrugosum. Besarnya kelimpahan Laevipilina cachuchensis disebabkan oleh morfologinya yang tipis dan melekat kuat pada substrat bebatuan. Tubuh spesies ini sangat tipis dan melebar ketika terkena ombak sehingga mampu bertahan pada tempatnya [17]. Sedangkan, spesies Morula margariticola memanfaatkan area di celah bebatuan sebagai tempat berlindung dari arus ombak. Spesies ini bertahan dari deburan ombak dengan melekat pada permukaan substrat berupa karang atau hidup membenamkan diri di pasir di antara celah karang untuk bertahan dari arus pantai [18].

Indeks keanekaragaman Moluska pada stasiun 1 , stasiun 2 , stasiun 3 perairan laut berturut-turut adalah 0,$37 ; 0,36 ; 0,32$ (Tabel 2). Hal ini menunjukkan bahwa indeks keanekaragaman pada ketiga stasiun tersebut termasuk rendah. Keanekaragaman yang rendah pada ketiga stasiun dapat disebabkan oleh kuatnya arus laut yang mencapai permukaan substrat berupa pasir maupun bebatuan sehingga hanya beberapa spesies Moluska tertentu saja yang dapat bertahan hidup. Berdasarkan pengamatan, jumlah plankton dan ganggang yang sedikit menyebabkan beberapa spesies tidak mampu bertahan hidup.

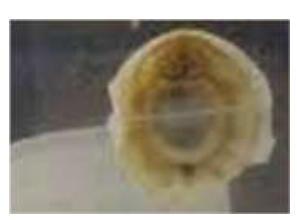

(a)

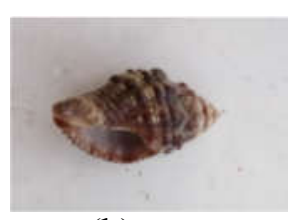

(b)

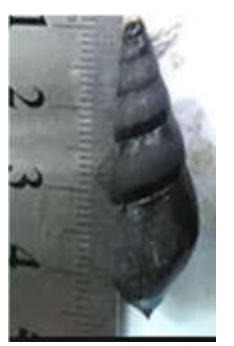

(c)

Gambar 4. Dokumentasi spesies Moluska yang ditemukan di area penelitian. a) Laevipilina cachuchensis; (b) Morula margariticola; (c) Thiara scabra

Spesies Moluska ditemukan lebih banyak di perairan Pantai Carita dibandingkan dengan di perairan tawar. Namun, indeks 
keanekaragaman di perairan Pantai Carita lebih rendah. Hal ini menunjukkan bahwa komunitas Moluska di perairan Pantai Carita cenderung seragam. Limbah dari perairan tawar menuju perairan laut sehingga hanya beberapa spesies yang toleran terhadap perubahan lingkungan. Pada kenyataannya, lokasi penelitian perairan laut dekat dengan muara sungai.

Indeks dominansi ketiga stasiun berturutturut adalah $0,12,0,21$, dan 0,04 sehingga termasuk dalam kategori rendah (Tabel 2). Hal ini menunjukkan bahwa tidak terjadi dominansi dari spesies tertentu sehingga menjadi ciri bahwa lingkungan Pantai Carita dalam keadaan sehat. Tingkat dominansi dapat dipengaruhi oleh faktor makanan berupa makrobenthos. Berdasarkan tingkat kelas ditemukan bahwa Gastropoda lebih dominan dibandingkan Bivalvia. Umumnya, Bivalvia hidup pada daerah berlumpur [19] sedangkan Pantai Carita dominan berpasir dan berkarang sehingga jenis Bivalvia yang ditemukan sedikit. Cara hidup Gastropoda yang dapat bergerak dan mempertahankan diri dari deburan ombak adalah faktor utama adanya dominansi dari Kelas Gastropoda.

Spesies Moluska dengan kelimpahan terbesar yang ditemukan di perairan tawar adalah Thiara scabra dengan nilai kelimpahan berturut-turut pada tiga statiun pengamatan $3,67,4,67$, dan $5,33 \mathrm{ind} / \mathrm{m}^{2}$. Thiara scabra merupakan siput dengan cangkang berukuran kecil, tinggi cangkang 25-30 mm dan garis tengah $13 \mathrm{~mm}$. Cangkang agak gemuk pendek sampai agak langsing dengan sulur meruncing. Warna cangkang cokelat atau krem kecokelatan hingga kehitaman. Besarnya kelimpahan spesies Thiara scabra dapat disebabkan karena morfologinya yang adaptif dengan substrat di area perairan tawar KHDTK yaitu didominasi bebatuan dan endapan lumpur. Hasil perhitungan indeks keanekaragaman Moluska pada stasiun 1, stasiun 2, stasiun 3 perairan tawar berturutturut adalah sebesar 0,36, 0,36, dan 0,37. Hal ini menunjukkan bahwa indeks keanekaragaman pada semua stasiun pengamatan tergolong rendah karena $H^{\prime}<2$. Indeks dominansi dari semua stasiun berturutturut $0,8,0,10$, dan 0,17 sehingga termasuk dalam kategori dominansi sedang menuju tinggi.

Parameter lingkungan. Berdasarkan analisis kualitas lingkungan menggunakan parameter suhu, kedalaman, kecepatan arus air, dan $\mathrm{pH}$ menunjukkan bahwa Pantai Carita dan perairan tawar di wilayah KHDTK tergolong baik untuk pertumbuhan Moluska (Tabel 3).

Tabel 3. Hasil pengukuran beberapa parameter fisika-kimia perairan di lokasi penelitian.

\begin{tabular}{|c|c|c|c|c|c|c|c|}
\hline \multirow[t]{2}{*}{ No } & \multirow[t]{2}{*}{$\begin{array}{l}\text { Parameter } \\
\text { Lingkungan }\end{array}$} & \multicolumn{3}{|c|}{$\begin{array}{c}\text { Stasiun } \\
\text { Perairan } \\
\text { Tawar }\end{array}$} & \multicolumn{3}{|c|}{$\begin{array}{c}\text { Stasiun } \\
\text { Perairan Laut }\end{array}$} \\
\hline & & 1 & 2 & 3 & 1 & 2 & 3 \\
\hline 1 & Suhu ("C) & 27 & 25 & 25 & 29 & 30 & 30 \\
\hline \multirow[t]{2}{*}{2} & Kedalaman/ & & & & & & \\
\hline & $\begin{array}{l}\text { Kecerahan } \\
(\mathrm{cm})\end{array}$ & 35 & 36 & 39 & 42 & 34 & 20 \\
\hline 3 & $\begin{array}{l}\text { Kecepatan arus } \\
\text { air }(\mathrm{m} / \mathrm{dt})\end{array}$ & 0,31 & 0,18 & 0,06 & 0,89 & 0,10 & 0,10 \\
\hline 4 & $\begin{array}{l}\text { Kelembaban } \\
(\%)\end{array}$ & 92 & 90 & 90 & 100 & 100 & 100 \\
\hline 5 & $\mathrm{pH}$ & 7 & 7 & 7 & 7 & 7 & 7 \\
\hline
\end{tabular}

Pada hasil pengukuran parameter fisikakimia perairan laut didapatkan bahwa suhu berkisar $29-30^{\circ} \mathrm{C}$, kisaran baik untuk pertumbuhan makrobentos, alga, dan plankton sebagai sumber makanan utama yang mendukung kehidupan Moluska. Kedalaman berkisar 20-42 cm yang dapat ditembus cahaya dan baik bagi pertumbuhan alga. Kecepatan arus laut berkisar $0,89-0,1 \mathrm{~m} / \mathrm{dt}$ tergolong sedang. Jika dikaitkan dengan struktur morfologi Bivalvia yang terbatas alat gerak maka diasumsikan Bivalvia yang dominan. Namun pada kenyataannya, Gastropoda yang banyak ditemukan. Gastropoda Thiara scabra merupakan spesies adaptif dan tahan terhadap limbah air [20]. Selanjutnya, kelembaban udara berkisar $90-100 \%$ dan sangat baik untuk pertumbuhan Moluska karena kelembaban udara yang tinggi menyebabkan suhu udara turun. Moluska menyenangi perairan dengan kisaran $\quad 25-30^{\circ} \mathrm{C}$. Kelembaban $100 \%$ disebabkan oleh pengaruh uap air laut pada waktu pengidentifikasian sekitar pukul 14.0016.00 WIB. Nilai $\mathrm{pH}$ air 7 dan sangat baik untuk perkembangan Moluska.Kualitas perairan Pantai Carita tergolong baik dan sesuai dengan baku mutu air untuk kehidupan biota laut berdasar Kepmen LH No. 51 tahun 2004.

Berdasarkan hasil pengukuran parameter lingkungan perairan tawar diperoleh data, kedalaman berkisar $35-39 \mathrm{~cm}$ yang dapat ditembus cahaya. Kecepatan aliran atau arus perairan tawar berkisar $0,06-0,31 \mathrm{~m} / \mathrm{dt}$ yang tergolong rendah. Adapun $\mathrm{pH}$ yang dimiliki yaitu 7. Menurut Hynes [21] hewan Gastropoda air tawar umumnya dapat hidup secara optimal pada lingkungan dengan kisaran 
$\mathrm{pH}$ 5,0-9,0, maka berdasarkan pernyataan tersebut, derajat keasaman perairan tawar KHDTK tergolong baik untuk menjadi tempat perkembangbiakan Moluska.

\section{KESIMPULAN}

Komunitas Moluska di KHDTK Carita teridentifikasi sebanyak 33 spesies Gastropoda, tiga spesies Bivalvia, dan satu spesies Monoplacophora pada perairan laut sedangkan empat spesies Gastropoda pada perairan tawar. Kelimpahan Moluska di perairan laut lebih rendah daripada perairan tawar. Spesies dominan yang ditemukan pada perairan laut adalah Laevipilina cachuchensis $\left(4,00 \mathrm{ind} / \mathrm{m}^{2}\right)$ dan Mactra grandis margariticola (1,67 $\mathrm{ind} / \mathrm{m}^{2}$ ) sedangkan spesies melimpah pada perairan tawar adalah Thiara scabra (4,56 ind $/ \mathrm{m}^{2}$ ). Keanekaragaman Moluska di perairan laut lebih rendah daripada perairan tawar dengan indeks keanekaragaman rata-rata adalah 0,35 dan 0,36. Parameter lingkungan berupa suhu, kedalaman, kelembaban, kecepatan arus, dan $\mathrm{pH}$ di perairan laut dan tawar tergolong baik untuk pertumbuhan Moluska.

\section{DAFTAR PUSTAKA}

[1] Udayantha H, Munasinghe D (2009) Investigation of the factors that influence on the distribution of mollusk, Faunus sp. (Mollusca: Gastropoda: Thiaridae along the Lunuwila Ela, Galle. Ruhuna Journal of Science 4(1): 65-74.

[2] Montesinos-Navaro A, Estrada A, Font $\mathrm{X}$, Matias MG, Meirelles C, Mendoza M, Honrado JP, Prasad HD, Vicente JR, Early R (2018) Community structure informs species geographic distribution. PLoS ONE 13(5): e0197877. doi.org/10.1371/journal.pone.0197877.

[3] Schowalter TD (1996) Insect ecology: An ecosystem approach. San Diego: Academic.

[4] Putro SP (2017) The Roles of Macrobenthic Mollusks as Bioindicator in Response to Environmental Disturbance: Cumulative k-dominance Curves and Bubble Plots Ordination Approaches. Earth and Environmental Science, IOP Publishing.

[5] Veras DR, Martins IX, Cascon HM (2013) Molluscs: How are they arranged in the rocky intertidal zone. Iheringia, Serie Zoologia. Porto Alegre 103(2): 97103.

[6] Dibyowati L (2009) Keanekaragaman Moluska (Bivalvia dan Gastropoda) di Sepanjang Pantai Carita, Pendeglang Banten. Skripsi. Bogor: Institut Pertanian Bogor.

[7] Silvestre G (1992) The Coastal Resources of Brunei Darussalam: Status, Utilization and Management. Manila: Worldfish.

[8] Tunnel JW (2010) Encyclopedia of Texas seashells: Identification, ecology, distribution, and history. Tecas: A\&M University.

[9] Sturm CF, Pearce TA, Valdes A (2006) The mollusks: A guide to their study, collection, and preservation. Boca Raton: Universal.

[10] Dillon RT (2004) The ecology of Freshwater. London: Cambridge University.

[11] Carpenter KE, Niem VH (1998) FAO Species identification guide for fishery purposes. the living marine resources of the Western Central Pasific Volume 2. Cephalopods, Crustaceans, Holothurians, and Sharks. Food and Agriculture Organization of the United Nations. Rome.

[12] Yasman. (1998) Struktur komunitas Gastropoda (Moluska) hutan mangrove di Pantai Barat Pulau Handeulum, Taman Nasional Ujung Kulon dan Pantai Utara Pulau Penjaliran Barat, Teluk Jakarta: Studi Perbandingan dalam Prosiding Seminar VI.

[13] Monalisha S, Edward JK (2015) Biodiversity of marine mollusk from selected locations of Andhra Pradesh Coast, South eastern India. Indian Journal of Geo-Marine Sciences 44(6): 842-855.

[14] Anandaraj T, Balasubramanian V, Murugesan P, Muthuvelu S (2012) Biodiversity of marine Mollusc in east coastal area of Thanjavur District, Tamil Nadu, India. Pharma and Biol. Archives. 3(1): 131-133.

[15] Datta SN, Chakraborty SK, Jaiswar AK, Ziauddin G (2010) A comparative study on intertidal fauna biodiversity of selected beaches of Mumbai coast. Journal of Environmental Biology 31(6): 981-986. 
[16] Williams GA, Morritt D (1995) Habitat partitioning and thermal tolerance in tropical limpet, Cellana grata. Marine Ecology Progress Series 124: 89-103.

[17] Urgorri V, Alvarez OG, Luque A (2005) Laevipilina Cachuchensis, a new Neopilinid (Mollusca: Tryblida) from off North Spain. Journal of Molluscan Studies 71(1): 59-66.

[18] Ginting ED, Susetya IE, Patana P, Desrita (2017) Identifikasi jenis-jenis Bivalvia di Perairan Tanjungbalai, Provinsi Sumatera Utara. Acta Aquatics 4(1): 13-20.

[19] Dolorosa, Roger G, Floredel DanganGalon (2014) Species richness of bivalves and gastropods in Iwahig River-Estuary, Palawan, the Philippines. International Journal of Fisheries, and Aquatic Studies 2(1): 207-215.

[20] Tarwotjo U, Rahadian R, Hadi M (2018) Community structure of macrozoobenthos as bioindicator of pepe river quality, Mojosongo, Boyolali. Journal of Physics: Conference Series 1025(2018): 012039.

[21] Hynes HB (1987) The Biology of polluted waters. London: Liverpool University. 